ARCHIVO ESPAÑOL DE ARTE, LXXXIII, 332

OCTUBRE-DICIEMBRE 2010, pp. 363-376

ISSN: 0004-0428

\title{
VARIA
}

\section{UNA SAGRADA FAMILIA DE OTTO VAN VEEN DEL ANTIGUO CONVENTO DE SANTA CLARA DE ORDUÑA EN VITORIA}

\begin{abstract}
Este estudio atribuye a Otto van Veen un lienzo de la Sagrada Familia en un interior que está en la iglesia de San Antonio del convento de clarisas de Vitoria-Gasteiz, procedente del antiguo convento de la misma orden de la ciudad de Orduña. Figura en todos los catálogos como anónimo, pero el análisis estilístico de la pintura y la comparación con otras obras de Van Veen son prueba para incluirlo dentro de su producción.

Palabras clave: Otto van Veen; Pintura flamenca; siglo XVI; Vitoria-Gasteiz; Orduña; Sagrada Familia.

The author attributes to Otto van Veen the Holy Family in an interior from the former convent of St. Claire in Orduña, today in the church of San Antonio in the convent of St. Claire in Vitoria-Gasteiz. Until now considered to be anonymous, stylistic analysis and comparison with other works by Van Veen demonstrate that it is by his hand.

Key words: Otto van Veen; Flemish Painting; XVIth Century; Vitoria-Gasteiz; Orduña; Holy Family.
\end{abstract}

En la iglesia de San Antonio de la ciudad de Vitoria está, desde hace poco tiempo, un lienzo de la Sagrada Familia procedente del antiguo convento de clarisas de Orduña $(220 \times$ $170 \mathrm{~cm}$.) (fig. 1). Figura sin autor, y Micaela Portilla lo recoge en el vasto catálogo monumental de la provincia de Álava como "interesante pintura al óleo del siglo XVIII". Situado en el coro alto del convento de Santa Clara de Orduña su estado de conservación era muy precario, con importantes pérdidas de policromía y roturas en la parte baja del lienzo ${ }^{2}$. Su restauración ha recuperado su antiguo esplendor y hace justicia a las palabras de la historiadora vasca que, a pesar del deterioro de la obra, fue capaz de advertir "una pintura de buena técnica y colorido"3.

El Niño Jesús centra la escena. Sedente en el regazo de su madre mira de frente, alzando su mano derecha en gesto de bendición. Lleva una sencilla túnica blanca que deja al descubierto sus rollizas piernas. La Virgen acomodada en una bella alfombra de decoración floral que la aísla del frío suelo enlosado, tiene la monumental prestancia de las matronas. Su manto azul cayendo sobre los hombros y cubriendo sus piernas acentúa el esquema piramidal clásico que dibuja su

1 Portilla Vitoria, M. [col. Iturrate Sáenz de Lafuente, J. \& González de Langarica Ruiz de Gauna, A.], Catálogo monumental de la Diócesis de Vitoria. Las vertientes cantábricas del noroeste alavés. La ciudad de Orduña y sus aldeas, VI, Vitoria-Gasteiz, 1988, p. 728.

${ }^{2}$ La imagen que se reproduce en el catálogo monumental mencionado es prueba de ésto. Idem, fig. 510.

${ }^{3}$ Idem, p. 728 . 


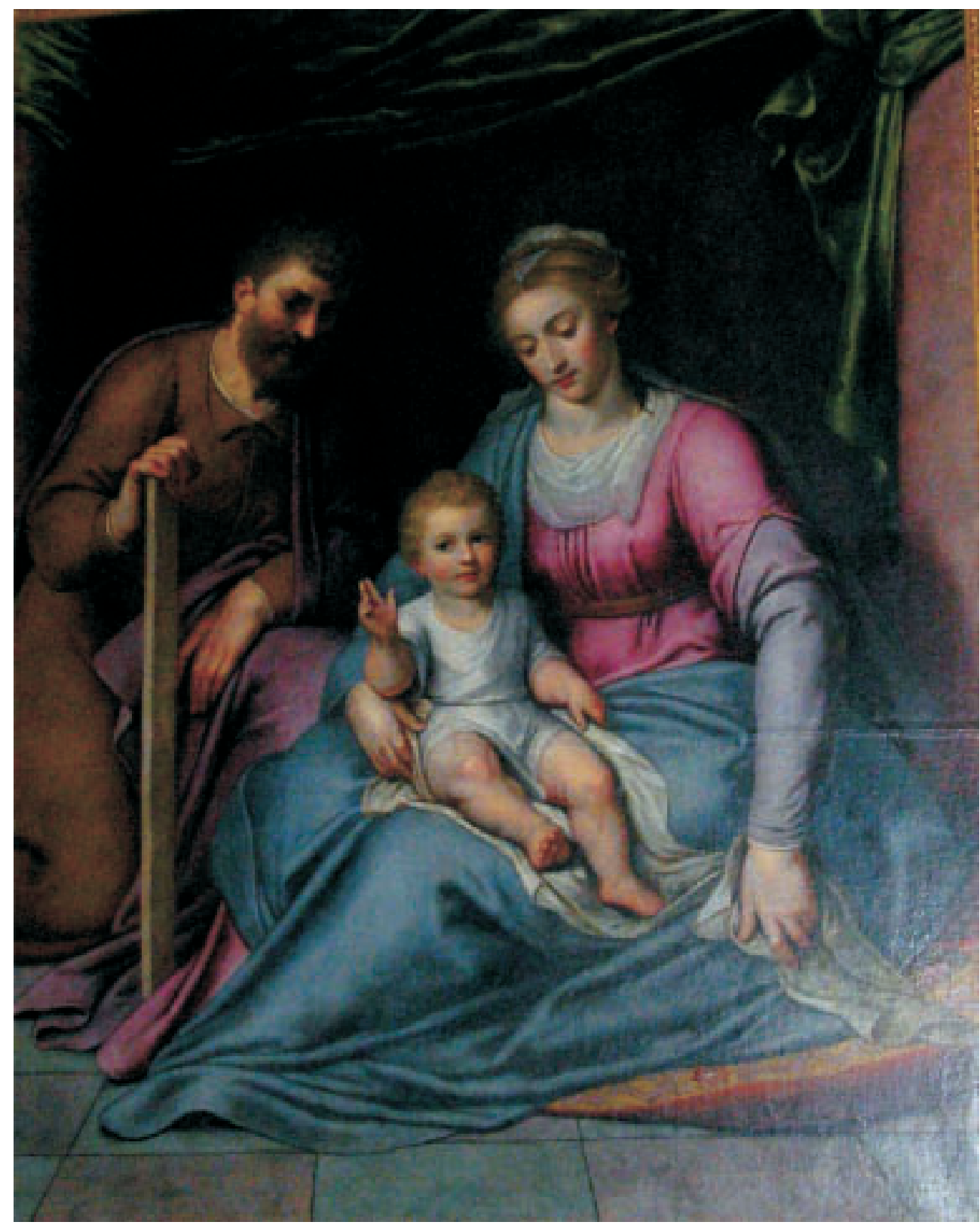

Fig. 1. O. van Veen, Sagrada Familia. Iglesia de San Antonio, Vitoria-Gasteiz.

figura recortada sobre el fondo arquitectónico de austera apariencia. Viste siguiendo la moda del momento para las gentes sencillas. Lleva un vestido rosado de manga tres cuartos que recoge a media altura con un pequeño botón, y camisa grisácea de manga larga. Un fino velo oculta el escote y parte del cabello en un tocado recogido en lo alto, fijado por una trenza que cruza la cabeza. Una esquina del velo se adelanta hacia la frente sin llegar a tocarla y marcando la división del cabello. La mano izquierda paralela al cuerpo y sujetando el paño de pureza sobre el 
que está Jesús, marca una diagonal que dirige la mirada hacia la figura de San José. Caracterizado como hombre joven de castaños y ensortijados cabellos y barba corta. Se arrodilla para atender al Niño, mientras apoya su mano derecha sobre un travesaño de madera, signo de su labor como carpintero. Viste túnica anaranjada abotonada en el centro sobre una camisa de la que sólo se ve el cuello. Se cubre con un manto malva. Su pose y la de la Virgen, con las cabezas inclinadas la una hacia la otra, dan lugar a una estructura piramidal que engloba a los tres personajes en un esquema clásico y monumental dentro de un rico interior de columnas de piedra y cortinaje verdoso de raso, que une los dos fustes y cubre las figuras a modo de baldaquino. Esta escena emana una tierna melancolía que anuncia la futura Pasión del Niño, sereno en los brazos de su madre. No sólo la mirada de la Virgen sino también la de San José preludian la muerte del pequeño.

La clásica composición, la monumentalidad casi escultórica, el colorido suave con predominio de rosados y los tipos idealizados pudo ser motivo para considerarla una pintura del siglo XVIII. Pero la técnica y los modelos vinculan el lienzo con el trabajo de Otto van Veen durante el periodo de 1595 a $1610^{4}$. Para Van Puyvelde las figuras de gran tamaño en primer plano, ocupando casi todo el espacio, y donde los tonos malvas y rosados predominan son un recurso que Van Veen toma de Giorgio Vasari tras su vuelta de Italia ${ }^{5}$, y que

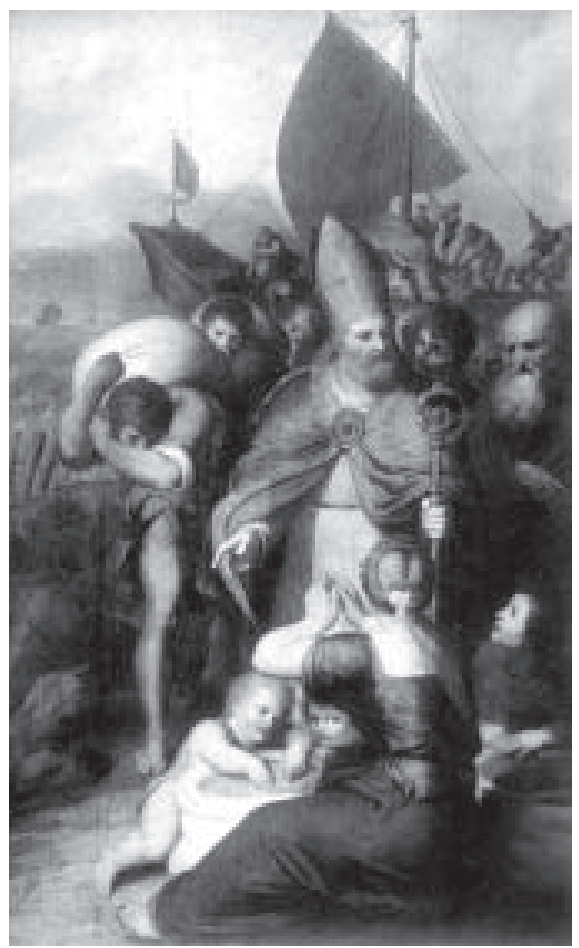

Fig. 2. O. van Veen, San Nicolás salvando de la hambruna a los habitantes de Amberes. Koninklijk Museum voor Schone Kunsten, Amberes. tuvo mayor repercusión durante el periodo señalado. Momento en que realiza el altar mayor para la iglesia de San Andrés de Amberes ${ }^{6}$, el Salvamento de la hambruna por San Nicolás del museo de la misma ciudad $^{7}$ (fig. 2); la Crucifixión del tríptico de la Pasión del museo de Bélgica (fig. 3); la Adoración de los pastores de la Maagdenhuis de Amberes ${ }^{8}$; y la Resurrección de Lázaro de la catedral de San Babón de Gante, de 1608. Con todas estas obras comparte modelos. El rostro de San José es similar al de de San Nicolás del lienzo citado; y la mujer llorando en la esquina derecha de la Crucifixión del museo de Bélgica recuerda en su monumentalidad y pose a la de la Virgen de Orduña que estudiamos. Incluso repite el mismo tipo de tocado, que retoma el pintor en la Adoración de los pastores de la Maagdenhuis de Amberes. Pintura que sigue el mismo esquema de rostro para la Virgen y San José que ésta. La pose de la Virgen con la mano izquierda cayendo recta paralela a su cuerpo la recupera para la figura femenina de la esquina derecha, mirando al espectador, de la Resurrección de Lázaro de la catedral de San Babón de Gante, ya citada.

\footnotetext{
${ }^{4}$ MüLler-Hofstede, J., "Zum werke des Otto van Veen 1590-1600”, Bulletin des Musees Royaux des Beaux Arts de Belgique, 1957, pp. 138-142.

${ }^{5}$ Van Puyvelde, L., La peinture flamande au siècle de Bosch et Breughel, París, 1962, p. 388.

${ }^{6}$ Obra fechada entre 1594 y 1599. VISSCHERS, P., Geschiedenis van de Sint-Andrieskerk te Antwerpen, I, Anvers, 1853 , p. 69.

7 Encargada por la guilda de merceros para su capilla en la catedral de Amberes.

${ }^{8}$ Obra de 1601. Geudens, A., Les tableaux des Hospices Civils d'Anvers, Anvers, 1904, p. 31.
} 


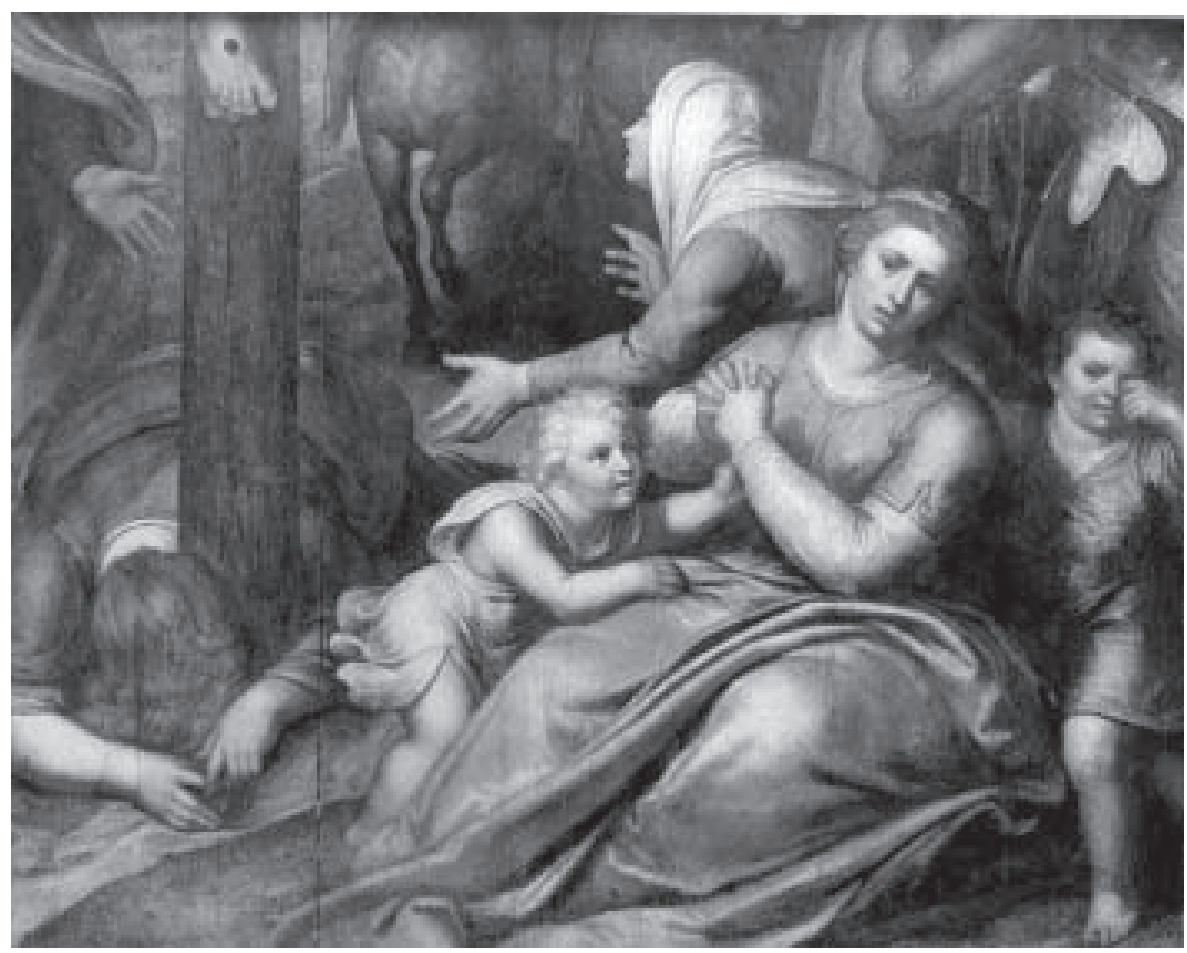

Fig. 3. O. van Veen, Detalle de la Crucifixión. Musées Royaux des Beaux-Arts de Belgique, Bruselas.

Los gruesos plegados de los ropajes que aquí emplea, y la idealización de los rostros es propia de Van Veen a fines del siglo XVI y principios del XVII, en el que los gestos comedidos acentúan las composiciones cerradas, de fuerte impronta clásica. El punto de vista ligeramente elevado de este lienzo y detalles accesorios, como la gruesa alfombra los repite en la Santa Cena de la catedral de Amberes.

La aparente sencillez compositiva de esta pintura de Orduña esconde una compleja lectura iconográfica. Ante esta tierna escena cotidiana de la vida de una familia se oculta una simbología más erudita para un espectador ilustrado. Jesús está sentado sobre su Madre, identificada con el modelo bizantino de la Sedes Sapientiae y la imagen de la Iglesia. San José con el madero en la mano, atributo de su condición de carpintero, y el manto de color morado que le cubre hace referencia a la Pasión y al sacrificio que debe pasar Jesús para así redimir a la Humanidad. El tema de la Sagrada Familia como género independiente tuvo gran popularidad a partir del Renacimiento y la Contrarreforma a raíz de las meditaciones franciscanas ${ }^{9}$, que favorecieron el culto de la "Trinidad humana" en contraposición a la divina. Este nuevo modelo iconográfico fue llamado también "Trinidad jesuita", por ser la orden de San Ignacio de Loyola su más ferviente difusora ${ }^{10}$. Los tres personajes pasan a ser identificados con las tres personas de la Trinidad

9 MÂle, E., El Barroco. Arte Religioso del siglo XVII. Italia, Francia, España, Flandes, ed. Madrid, 1985, p. 282.

${ }^{10}$ Idem, p. 283; RÉAU, L., Iconographie de l'Art Chrétien. Iconographie de la Bible, I/II, Paris, 1957, p. 150. 
divina: San José se corresponde con el Padre, la Virgen con el Espíritu Santo y el Niño queda como punto de intercesión de ambas Trinidades ${ }^{11}$.

Hay documentos que señalan que este tema de la Sagrada Familia fue trabajado en otras ocasiones por Otto van Veen. En el mercado artístico europeo aparecen varias descripciones de Sagradas Familias atribuidas a este pintor. Sobre tabla se citan en la galería G. Lavillarmois de Lille en 1799; y galería Van Geel de Mechelen en 1840. Sin especificar su soporte pero sí su calidad aparecen en 1764 en la galería Jaupain en Bruselas; galería Jean van Hese de Brujas en 1803; y galería Moor de Brujas en 1808. En 1814 se describe un lienzo de "Une Sainte Famille. La Vierge assise tient l'enfant Jesus sur ses genoux; à gauche est St-Joseph. Ce tableau joint à un parfait coloris, un ton hardi et du meilleur effet" ${ }^{\prime 2}$.

Otto van Veen fue pintor de gran cultura (Leiden, 1556-Bruselas, 1629). Conocido como pictor doctus por su formación dentro de los círculos humanistas y eruditos de Justus Lipsius y Lampsonius ${ }^{13}$, que completó tras su viaje a Italia donde entra en relación con los Zuccaro y la obra de los romanistas italianos. La conjunción de influencias manieristas y clasicistas que trae a Flandes la emplea indistintamente dependiendo del asunto que trata ${ }^{14}$. Esta Sagrada Familia viene a engrosar la lista de pinturas de este artista y humanista nórdico, más conocido por su labor como maestro de Rubens ${ }^{15}$, y su faceta emblemática ${ }^{16}$, que cómo pintor. Adolece de una revisión de toda su obra pictórica. Hay aproximaciones a periodos concretos y obras específi$\operatorname{cas}^{17}$, pero sería muy necesario un estudio que lo aborde en todos sus campos. Karel van Man-

${ }^{11}$ Idem, pp. 150-151.

12 Galería Jean François de Vinck de Wesel, Amberes, 16 de agosto de 1814. Sus medidas en pulgadas equivaldrían, más o menos, a $109 \times 82 \mathrm{~cm}$.

${ }^{13}$ Estuvo al servicio de Alejandro Farnesio, duque de Parma, los archiduques Alberto e Isabel, y de Rodolpho II de Praga. Bertini, G., "Otto van Veen, Cosimo Masi and the Art Market in Antwerp at the end of the Sixteenth Century", The Burlington Magazine, February, 1998, pp. 119-120.

14 Vlieghe, H., Arte y arquitectura flamenca, 1585-1700, Madrid, 2000, p. 45.

15 Haberditzl, F., "Die Leherer des Rubens", Jahrbuch der Kunsthistorisches Sammlung des allerhöchsten Kasierhauses in Wien, XXVII, 1907-1909, pp. 191-235; Müller-Hofstede, J., “Zum Werke ...”, op. cit., VI, 1957, pp. 127-174; Müller-Hofstede, J., Otto van Veen, der Lehrer des P.P. Rubens, Tesis doctoral inédita, Universidad de Freiburg im Breisgau, 1959; BAudorn, F., "Een jeugdwerk van Rubens, Adam en Eva en de relatie van Veen en Rubens", Antwerpen, 1968, pp. 45-61; Vlieghe, H., "Rubens and Van Veen in Contest", en Ars Aura prior. Studia Ioanni Bialostocki, Varsovia, 1981, pp. 477-482; Held, J., Rubens and his Circle, Princeton, 1982, pp. 59-60, 116; Morford, M., Stoics and Neostoics. Rubens and the Circle of Lipsius, Princeton, 1991, pp. 38, 187-189.

16 Wilberg Vignau-Schuurman, T., "Joris Hoefnagels Groteskenserie en de Amorum Emblemata van Otto van Veen", Opstellen voor H. van de Waal, Leiden, 1970, pp. 214-232; Gerards-Nelissen, I., "Otto van Veens Emblemata Horatiana", Simiolus, 1971, pp. 20-63; Foster, L., "Die Emblemata Horatiana des Otto Vaenius", Wolfenbüttel Forsch, 1981, pp. 117-128; SeBAstián LóPeZ, S., "Theatro Moral de la Vida Humana de Otto Vaenius: Lectura y significado de los emblemas", Boletín del Museo e Instituto Camón Aznar, 14, 1983, pp. 7-92; SeBAStIÁN López, S., "Lectura crítica de la Amorum Emblemata de Otto Vaenius", Boletín del Museo e Instituto Camón Aznar, XXI, 1985, pp. 5-112; Sebastián LóPez, S., "La emblemática moral de Vaenius en Iberoamérica", Goya: Revista de arte, n. ${ }^{\circ}$ 234, 1993, pp. 322-329; Sebastián LóPez, S., La mejor emblemática amorosa del Barroco. Hensius, Vaenius y Hooft, El Ferrol, 2001; Escalera Pérez, D. R., "Los treinta amores sagrados. Otto Vaenius y el Corpus de Granada de 1801", en Los días de Alción: emblemas, literatura y arte del Siglo de Oro, Cull, 2002, pp. 179-192; López PozA, S., "El concepto neoestoico de 'sabio' y su difusión en la emblemática: el Theatro moral de Vaenius", en Modelos de vida en la España del Siglo de Oro, 2, 2007, pp. 147-190; T. Montone, “Horatius Emblematicus': genio e tecnica negli emblemi filosofici del maestro olandese Otto van Veen (Vaenius)" en Il concetto di libertá nel Rinascimento atti del XVIII Convegno Internazionale, Chianciano-Pienza, 17-20 luglio, 2006, Firenze, 2008, pp. 589-606.

${ }^{17}$ Hay estudios parciales de sus obras: Van Looveren, L., "Venationum novem archetypa" "Negen Allegorische Jachttaferelen door Otto van Veen", De Gulden Passer. Bulletin van de Vereeniging der Antwerpsche Bibliophielen, 
der ya lo incluye en su Schilderboek de $1604^{18}$, al igual que Vasari al hablar de los Zuccaro, y Descamps dice de él que es uno de los primeros en introducir el buen gusto en Flandes ${ }^{19}$.

La llegada del lienzo al convento de clarisas de Orduña es una incógnita. Aunque la presencia de religiosas en el convento con importantes familias residentes en Flandes a principios del siglo XVI, abren varias hipótesis acerca de su procedencia. Don Mateo de Urquina, secretario de los archiduques en Bruselas, tenía dos hijas en el convento orduñés, y establecía una capilla en la iglesia del convento en $1620^{20}$. Es posible que conociese a Otto van Veen, que a principios del siglo XVII era pintor de los Archiduques, y al que pudo encargar este lienzo para enviar a sus hijas a Orduña. Otro importante español residente en los Países Bajos del norte, con dos hijas en el convento de Santa Clara, fue Esteban de Gamarra y Contreras, consejero de guerra, maestre de campo en Flandes, legado ordinario del Rey para los Jefes de la Confederación de las Provincias de Bélgica y embajador en los Países Bajos del norte ${ }^{21}$. Durante las revueltas iconoclastas salvó reliquias de las iglesias y conventos expoliados que envió a sus hijas en Orduña. Se podría aventurar que, además de las reliquias salvadas, también incluyera alguna obra de pintura. Por último, don Juan Hurtado de Corcuera, orduñés residente en Flandes, tenía dos hermanas en el convento de Santa Clara a las que envía desde Amberes una importante cantidad de dinero en $1604^{22}$. Queda demostrada la relación directa del convento de Santa Clara con Flandes a través de importantes familias españolas residentes en los Países Bajos hispanos, por lo que la aparición de este lienzo flamenco de Otto van Veen entre sus pertenencias no es de extrañar.

ANA DiÉGuez RodRÍGuEZ Instituto Moll

1974, pp. 151-175; Foucart, J., “Quelques inédits d'Otto Venius”, en Rubens and his World, Amberes, 1985, pp. $97-$ 108; Volg, A., Der Bilderzyklus "Der Triumph der Kirche" von Otto van Veen, Munich, 1987; H. Ost, "Unbekannte Werke von Otto van Veen”, Wallraf-Richartz-Jahrbuch, 68 (2007), pp. 279-294; R. DeKOnINCK \& A. GUIDERDONI, Reasoning pictures: the Physical et Theologicae Conclusiones by Vaenius (1621), in Otto Vaenius and His Emblem Books, ed. Simon McKeown. Glasgow Emblem Studies 15 (Geneva: Droz, 2011, en prensa).

18 Van Mander, K., Het Schilderboek, 1604, ed. Hymans, H., Le Livre des Peintres de Carel van Mander, II, París, 1884, pp. 271-281; ed. Miedema, H., DoornsPiJK, 1999, I, p. 438; VI, pp. 52-58.

19 Descamps, J. B., La vie des Peintres Flamands, Allemands et Hollandois, I, Paris, 1753, p. 223.

20 Portilla Vitoria, M., [col. Iturrate Sáenz de Lafuente, J., \& González de Langarica Ruiz de Gauna, A.], Catálogo monumental de la Diócesis de Vitoria..., op. cit., VI, p. 720.

${ }^{21}$ Idem, p. 731

22 Idem, p. 733. 